\title{
Drosophila melanogaster alcohol dehydrogenase
}

\section{Biochemical properties of the $\mathrm{NAD}^{+}$-plus-acetone-induced isoenzyme conversion}

\author{
Jan-Olof WINBERG* and John S. McKINLEY-McKEE \\ Biochemical Institute, University of Oslo, Blindern, 0316 Oslo 3, Norway
}

The $\mathrm{NAD}^{+}+$acetone-induced isoenzyme conversion of the Drosophila melanogaster $\mathrm{Adh}^{\mathrm{s}}$ alleloenzyme was studied. Absorption and fluorescence spectra as well as electrophoretic and kinetic methods show that the conversion process proceeds through three steps. Initially a binary enzyme-NAD ${ }^{+}$complex is formed, followed by a ternary enzyme-NAD ${ }^{+}$-acetone complex with a $K_{\mathrm{EO}, \mathrm{Ac}}$ of $1.7 \mathrm{M}$. The last step is a rate-limiting irreversible process in which $\mathrm{NAD}^{+}$and acetone are covalently linked to the enzyme. A $V_{\mathrm{m}}$ of $2.4 \mathrm{~min}^{-1}$ was obtained at $\mathrm{pH}$ 8.6.

\section{INTRODUCTION}

The alcohol dehydrogenase enzyme from Drosophila melanogaster consists of multiple electrophoretic forms [1-5]. These arise from different $A d h$ alleles as well as post-translational modifications [1,6-13] (for nomenclature see Fig. 1 in ref. [12]). There is one polymorphic Adh locus in Drosophila melanogaster [2,14], and a lot of different allelic variants have been detected, purified and analysed [15-27]. A particular problem is the appearance of multiple variants in crude as well as purified Adh extracts from flies homozygous at the Adh locus. These forms can be interconverted artificially both in vivo $[9,11]$ and in vitro $[6,7,28,29]$. The nature of these multiple forms seems complex, with different mechanisms operating. By adding either secondary alcohols or ketones to the flies' food/agar or incubating crude or pure enzyme extracts with high concentrations of $\mathrm{NAD}^{+}$and a ketone, the Adh-5 form can be converted into more electronegative forms, i.e. Adh-3 and Adh-1. The nature of the forms produced in vitro and compared with those produced in vivo is unclear. The more electronegative forms of the enzyme have been assumed to be artifacts [16], to contain different amount of $\operatorname{NAD}^{+}[28,30]$, to be $\mathrm{NAD}^{+}-$ketone adducts $[8,10]$ or to be conformational isomers of the native Adh-5 form [7,31].

The present paper asks the following questions: do $\mathrm{NAD}^{+}$and acetone bind to the enzyme when Adh- 1 is produced from Adh-5, or do $\mathrm{NAD}^{+}$and acetone only serve as catalytical agents for a conformational change? If the former is the case, do both compounds bind to the enzyme and is the complex formed covalent or noncovalent? Likewise, what is the stoichiometry of the complex and the mechanism of the conversion process? It was also of interest to determine whether the activity zone of the converted enzyme that appears in zymography was a result of a non-enzymic reduction of the staining components.

\section{MATERIALS AND METHODS}

Tris, Nitro Blue Tetrazolium and $N$-methylphenazonium methosulphate were from Sigma Chemical Co.
Glycine and fluorescence-grade acetone were from Merck. Starch was obtained from Connaught Medical Research Laboratories. Ethanol $(96 \%, v / v)$ was from $\mathrm{A} / \mathrm{S}$ Vinmonopolet. $\mathrm{NAD}^{+}$and NADH were from Sigma Chemical Co. and Boehringer Mannheim. $\mathrm{NAD}^{+}$ from Sigma Chemical Co. was obtained as an acetone precipitate [32] whereas that from Boehringer was crystallized from quinoline, ethanol and benzene [33].

\section{Enzyme}

$\mathrm{Adh}^{\mathrm{s}}$ from Drosophila melanogaster was purified as described previously [12].

\section{Electrophoresis}

Horizontal starch-gel electrophoresis and activity staining were carried out as described previously [12].

\section{Rate assay}

To quantify the enzyme active-site concentration, an enzymic rate assay mixture containing $0.5 \mathrm{~mm}-\mathrm{NAD}^{+}$ and $100 \mathrm{~mm}$-ethanol in a total volume of $3 \mathrm{ml}$ of $0.1 \mathrm{M}$ glycine/ $\mathrm{NaOH}$ buffer, $\mathrm{pH} \mathrm{9.5,} \mathrm{at} 23.5^{\circ} \mathrm{C}$ was used [34].

\section{Spectra measurements}

Absorption and difference spectra were determined with a Perkin-Elmer $\lambda 115$ spectrophotometer and a Beckman DU 7 spectrophotometer.

Fluorescence emission spectra were determined with a Perkin-Elmer LS-5B luminescence spectrometer.

\section{Conversion and inactivation kinetics}

To convert Adh-5 into Adh-1, $9 \mu \mathrm{M}-\mathrm{Adh}^{\mathrm{S}}$ was incubated with $18 \mathrm{~mm}-\mathrm{NAD}^{+}$(Boeringer) and $240 \mathrm{~mm}$ acetone for $1.5 \mathrm{~h}$ at room temperature. This mixture was then dialysed against three changes of $0.1 \mathrm{M}-\mathrm{Tris} / \mathrm{HCl}$ buffer, $\mathrm{pH}$ 8.6, to remove unbound $\mathrm{NAD}^{+}$and acetone. This dialysed preparation was used to determine the absorption and fluorescence spectra of the converted enzyme.

As the converted enzyme preparation almost lacked enzymic activity, it was possible to investigate the conversion by inactivation kinetics. The inactivation

\footnotetext{
Abbreviations used: Adh, alcohol dehydrogenase (EC 1.1.1.1); Adh', 'slow' form of alcohol dehydrogenase from Drosophila melanogaster.

* Present address: Polar Institute of Medical Genetics, Regional Hospital and University of Tromsø, 9012 Tromsø, Norway.
} 
kinetics of the conversion process were studied as follows. Reaction was started by adding $20 \mu \mathrm{l}$ of $30 \mu \mathrm{M}$ enzyme subunits to a reaction mixture containing 3-10 mM$\mathrm{NAD}^{+}$(Boehringer) and 24-240 mM-acetone in a total volume of $200 \mu \mathrm{l}$ of $0.1 \mathrm{M}$-Tris/ $\mathrm{HCl}$ buffer, $\mathrm{pH} \mathrm{8.6,} \mathrm{at}$ $23.5^{\circ} \mathrm{C}$. At appropriate time intervals $20 \mu \mathrm{l}$ of the inactivation mixture was withdrawn and assayed by the enzymic rate assay. To eliminate uncertainty in the amount of enzyme added to the inactivation mixture, the inactivation curve was extrapolated to zero time to give $100 \%$ activity. The half-time $\left(t_{1}\right)$ of the inactivation reaction was obtained both graphically by plotting the inactivation curve on semi-logarithmic graph paper and by using linear regression on a Hewlett-Packard 11C calculator. The rate constant $\left(k^{\prime}\right)$ was determined from the half-time - by using $k^{\prime}=(\ln 2) / t_{\frac{1}{2}}$ [35]. If the inactivation reagent(s) is/are far above the enzyme concentration, the reaction order with respect to enzyme can be deduced directly from the inactivation curve (a semi-logarithmic plot of activity versus time) with the occurrence of straight lines for first-order reactions. To determine whether a reversible complex between the enzyme and inactivator(s) occurs before the irreversible reaction, the inactivation rate requires to be measured at different concentrations of inactivator(s). When a reversible complex is formed, both a maximum inactivation rate $\left(V_{\mathrm{m}}\right)$ and the dissociation constant of the reversible complex $\left(K_{\mathrm{i}}\right)$ can be deduced from the slopes and intercepts in a double-reciprocal plot. On the other hand, if the reversible complex is too weak or does not form, the plot will go through the origin. In the absence of formation of a reversible complex, the apparent firstorder rate constant $\left(k^{\prime}\right)$ for

$$
E+n I \stackrel{k}{\rightarrow} \mathrm{EI}_{n}
$$

(where $\mathrm{EI}_{n}$ denotes an irreversible inactive complex) depends on the concentration of I according to $k^{\prime}=k[\mathrm{I}]^{n}$ where $n$ is the order of the reaction with respect to I [36]. As $\log k^{\prime}=\log k+n \cdot \log [\mathrm{I}]$, a plot of $\log k^{\prime}$ versus $\log [\mathrm{I}]$ will have a slope of $n$, which gives an indication of the stoichiometry of the inactivation. However, if a reversible complex between enzyme and inactivator forms before inactivation, i.e.:

$$
\mathrm{E}+\mathrm{I} \stackrel{K_{1}}{\rightleftharpoons} \mathrm{EI} \stackrel{k}{\rightarrow} \mathrm{E}^{\prime} \mathrm{I}
$$

a plot of $\log k^{\prime}$ versus $\log [\mathrm{I}]$ will have a slope that approaches 1 if $[\mathrm{I}]<K_{\mathrm{i}} / 10$ and with larger [I] the slope will be less than 1 [37].

\section{RESULTS AND DISCUSSION}

An $\mathrm{NAD}^{+}$-carbonyl compound was isolated from the naturally occurring Adh-1 isoenzyme form from Drosophila melanogaster [10] and it was considered to be reversibly bound to the enzyme. Purified Adh-5 was converted into Adh-3 and Adh-1 by incubating the enzyme with a high concentration of either $\mathrm{NAD}^{+}$or acetone [7]. This artificially produced Adh-1 isoenzyme was considered to be different from the naturally occurring Adh-1 form as the former could not be reverted back into Adh-5. The conversion process was assumed to result from some impurities in the NAD ${ }^{+}$ preparations, and the Adh-1 form produced was considered to be a conformational isomer of Adh-5. It has been shown that neither pure $\mathrm{NAD}^{+}$nor acetone alone

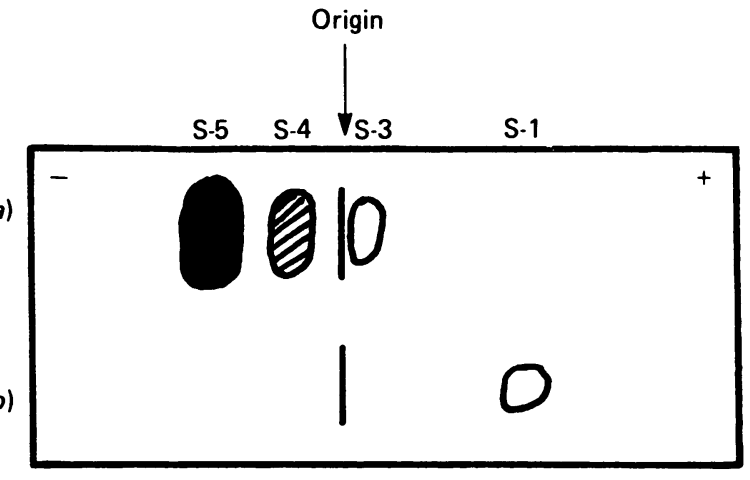

Fig. 1. Gel from starch-gel electrophoresis in $0.1 \mathrm{M}$-Tris/HCl buffer, pH 8.5, stained for alcohol dehydrogenase activity

(a) $\mathrm{Adh}^{\mathrm{s}}$; (b) the converted enzyme, i.e. $\mathrm{Adh}^{\mathrm{s}}$ preincubated with $\mathrm{NAD}^{+}$and acetone, dialysed against three changes of buffer.

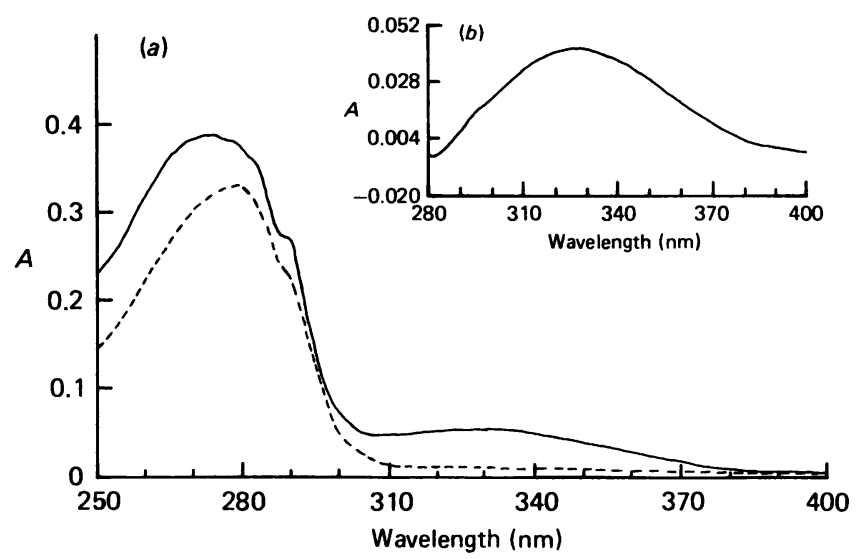

Fig. 2. Absorption and difference spectra of native and converted Adhs enzyme

(a) Absorption spectra: - , converted $\operatorname{Adh}^{\mathrm{S}}(5 \mu \mathrm{M})$; ----, native $\operatorname{Adh}^{\mathrm{s}}$ (5 $\left.\mu \mathrm{M}\right)$. (b) Difference spectrum of converted $\mathrm{Adh}^{\mathrm{s}}$ minus native $\mathrm{Adh}^{\mathrm{s}}$.

could convert Adh-5 into Adh-3 and Adh-1, but that together they induce the conversion [12]. To determine whether NAD ${ }^{+}$and acetone are bound to Adh-1 or not, the $\mathrm{Adh}^{\mathrm{s}}$ alleloenzyme from Drosophila melanogaster was converted into the Adh-1 form (Fig. 1). The converted enzyme was then dialysed against three changes of $0.1 \mathrm{M}$-Tris/ $\mathrm{HCl}$ buffer, $\mathrm{pH} \mathrm{8.6,} \mathrm{resulting} \mathrm{in} \mathrm{a}$ $10^{\circ}$-fold dilution of unbound $\mathrm{NAD}^{+}$and acetone. The Adh-1 form was not reverted back into Adh-5 by dialysis. This indicates that an irreversible change has occurred with Adh-1. The absorption spectrum in Fig. 2 shows that the $280 \mathrm{~nm}$ absorption peak of the native $\mathrm{Adh}^{\mathrm{S}}$ alleloenzyme has changed to $273 \mathrm{~nm}$ in the converted enzyme. This is as expected for an enzymecoenzyme complex. Fig. 2 also shows that the converted enzyme has an additional absorption peak at $328 \mathrm{~nm}$. This indicates the formation of a reduced nicotinamide compound, in this case most probably an NAD(H)acetone complex irreversibly bound to the enzyme. Table 1 lists the absorption peaks of different $\mathrm{NAD}^{+}$addition compounds and also the absorption maxima when these compounds are bound to either horse liver Adh or 
Table 1. Shifts in the absorption maximum of $\mathbf{N A D}^{+}$substituted at the 4-position of the nicotinamide moiety

After releasing an $\mathrm{H}^{+}$ion the addition compounds are assumed to be bound covalently to $\mathrm{C}-4$ of the nicotinamide ring, resulting in the conversion into 4-substituted $\mathrm{NAD}^{+}$ compounds.

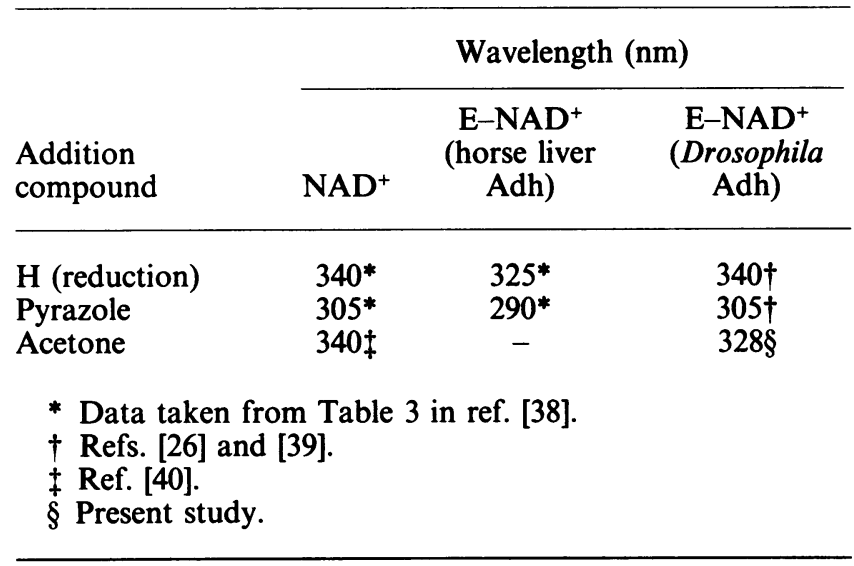

Drosophila Adh. The blue-shifts observed for some enzyme-NADH complexes have been suggested to be a result of either a non-polar environment [41] or a positive charge in the vicinity of the dihydropyridine ring [42]. Drosophila Adh differs from horse liver Adh as it lacks the blue-shift in the binary enzyme-NADH complex and in the ternary enzyme-NAD ${ }^{+}$-pyrazole complex. With Drosophila Adh, a 10-15 nm blue-shift appears when the ternary enzyme-NAD(H)-acetone complex is irreversibly formed (Table 1). This indicates that the nicotinamide moiety of the coenzyme in the converted enzyme does not share the same environment as the nicotinamide moiety of the coenzyme in the reversibly formed enzyme-NADH and enzyme-NAD ${ }^{+}$-pyrazole complexes. As the absorption coefficient $\epsilon_{340}$ for the $\mathrm{NAD}(\mathrm{H})$-acetone adduct is $4.5 \times 10^{3} \mathrm{M}^{-1} \cdot \mathrm{cm}^{-1}$ [40], the absorbance of 0.043 for the $328 \mathrm{~nm}$ absorption peak of the converted enzyme $(5 \mu \mathrm{M})$ indicates that the enzyme contains $9.3 \mu \mathrm{M}$ of bound coenzyme. This was also the case when the calculation was based on the absorbance difference at $260 \mathrm{~nm}$, which showed that the converted enzyme contained one coenzyme molecule per active site.

Both $\mathrm{NADH}$ and the $\mathrm{NAD}(\mathrm{H})$-acetone adduct give rise to fluorescence when the excitation wavelength is around their absorption spectrum maximum of $340 \mathrm{~nm}$ $[43,44]$. When NADH forms a binary complex with Drosophila Adh the wavelength maximum $\left(\lambda_{\max }\right)$ of the NADH fluorescence changes from $460 \mathrm{~nm}$ to $424 \mathrm{~nm}$ and a 20 -fold increase in the fluorescence intensity occurs $[26,39]$. This contrasts with the converted enzyme, where excitation at 325 or $330 \mathrm{~nm}$ resulted in a very low fluorescence compared with that of NADH, and no peak could be detected. This lack of fluorescence enhancement also indicates that the nicotinamide moiety of the coenzyme in the converted enzyme is exposed to an environment different from that in the reversibly formed enzyme-coenzyme complexes. A mixture of the converted enzyme $(5 \mu \mathrm{M})$ and $10 \mu \mathrm{M}-\mathrm{NADH}$ did not give rise to changes in the NADH fluorescence. The NAD $(\mathbf{H})$-acetone moiety of the converted enzyme blocks the catalytic site

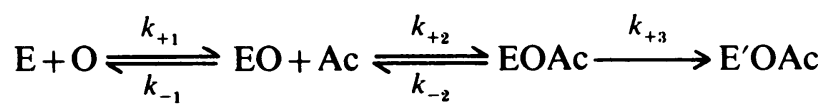

Scheme 1.

of the enzyme, and if a small portion of NADH is bound it is outside the detection limit of the method.

Previously it has been shown that alcohol-competitive inhibitors such as pyrazole $\left(K_{\mathrm{EO}, \mathrm{I}}=5 \mu \mathrm{M}\right)$, cyanide $\left(K_{\mathrm{EO}, \mathrm{I}}=20 \mu \mathrm{M}\right)$ and 2-mercaptoethanol $\left(K_{\mathrm{EO}, \mathrm{I}}=\right.$ $250 \mu \mathrm{M})$ prevents the conversion process $[7,12,26]$. Thus both $\mathrm{NAD}^{+}$and acetone must enter the enzyme active site before conversion takes place. As the converted enzyme was almost inactive in the spectrophotometric rate assay, inactivation kinetics were used to study the conversion process. In Fig. 3(a) the plots of $\log$ (velocity) versus time show that the conversion process is a first-order reaction with respect to enzyme. By using high concentrations of the inactivators (NAD ${ }^{+}$and acetone) compared with the enzyme, the inactivation reaction obeys a MichaelisMenten type of mechanism. If $\mathrm{NAD}^{+}$during the inactivation reaction binds to the coenzyme-binding region of the enzyme, $98-100 \%$ of the enzyme will be in the binary enzyme-NAD ${ }^{+}$complex (EO) as $K_{\mathrm{E}, \mathrm{o}}$ at pH 8.5 is $44 \mu \mathrm{M}$ (J.-O. Winberg \& J. S. McKinleyMcKee, unpublished work). In Fig. 3(c) the doublereciprocal plots of $k^{\prime}$ versus [acetone] were identical for the three $\mathrm{NAD}^{+}$concentrations, which showed that the $\mathrm{NAD}^{+}$concentrations were saturating. The plots also crossed the $1 / k^{\prime}$ axis and indicated saturation kinetics with reversible formation of ternary enzyme-NAD ${ }^{+}-$ acetone (EOAc) complex before inactivation. The inactivation/conversion reaction can be described as in Scheme 1, where $E^{\prime} O A c$ [enzyme-NAD(H)-acetone] is the irreversibly formed Adh-1 isoenzyme. Eqn. (1) describes this scheme in kinetic terms, where the rate constants can be determined from a double-reciprocal plot:

$$
\frac{1}{k^{\prime}}=\frac{1}{V_{\mathrm{m}}}+\frac{K_{\mathrm{a}}}{V_{\mathrm{m}}[\mathrm{O}]}+\frac{K_{\mathrm{b}}}{V_{\mathrm{m}}[\mathrm{Ac}]}+\frac{K_{\mathrm{E}, \mathrm{O}} K_{\mathrm{b}}}{[\mathrm{O}][\mathrm{Ac}]}
$$

$\mathrm{NAD}^{+}$is denoted by $\mathrm{O}$, acetone by Ac, $V_{\mathrm{m}}=k_{+3}$, $K_{\mathrm{a}}=k_{+3} / k_{+1}, K_{\mathrm{b}}=\left(k_{-2}+k_{+3}\right) / k_{+2}$ and $K_{\mathrm{E}, \mathrm{o}}=k_{-1} / k_{+1}$. With saturating $\mathrm{NAD}^{+}$concentrations, eqn. (1) becomes:

$$
\frac{1}{k^{\prime}}=\frac{1}{V_{\mathrm{m}}}+\frac{K_{\mathrm{b}}}{V_{\mathrm{m}}[\mathrm{Ac}]}
$$

At pH $8.6,1 / V_{\mathrm{m}}$ is $0.4 \mathrm{~min}$ and $V_{\mathrm{m}}$ is $2.4 \mathrm{~min}^{-1}$. With $k_{-2}$ considered much larger than $k_{+3}, K_{\mathrm{b}}=k_{-2} / k_{+2}$, the dissociation constant of acetone from the ternary complex $K_{\mathrm{EO} \text { Ac }} . K_{\mathrm{b}}$ is $1.7 \mathrm{M}$ and shows that acetone is weakly bound to the enzyme- $\mathrm{NAD}^{+}$complex. A straight line with a slope of 0.93 occurs in the plot of $\log k^{\prime}$ versus $\log$ [acetone] (Fig. 3b). As the acetone concentrations ranges from $K_{\mathrm{b}} / 7$ to $K_{\mathrm{b}} / 70$, the slope of 0.93 indicates that conversion is complete after one molecule of acetone is bound per active site.

The Drosophila isoenzyme Adh-1 is regarded as inactive in spectrophotometric assays $[7,45,46]$. However, the detection of this isoenzyme form by the phenazine methosulphate/Nitro Blue Tetrazolium activity staining method after electrophoresis has been regarded as either the electrophoresis procedure reversing the inactivation of the converted enzyme [7] or the phenazine metho- 

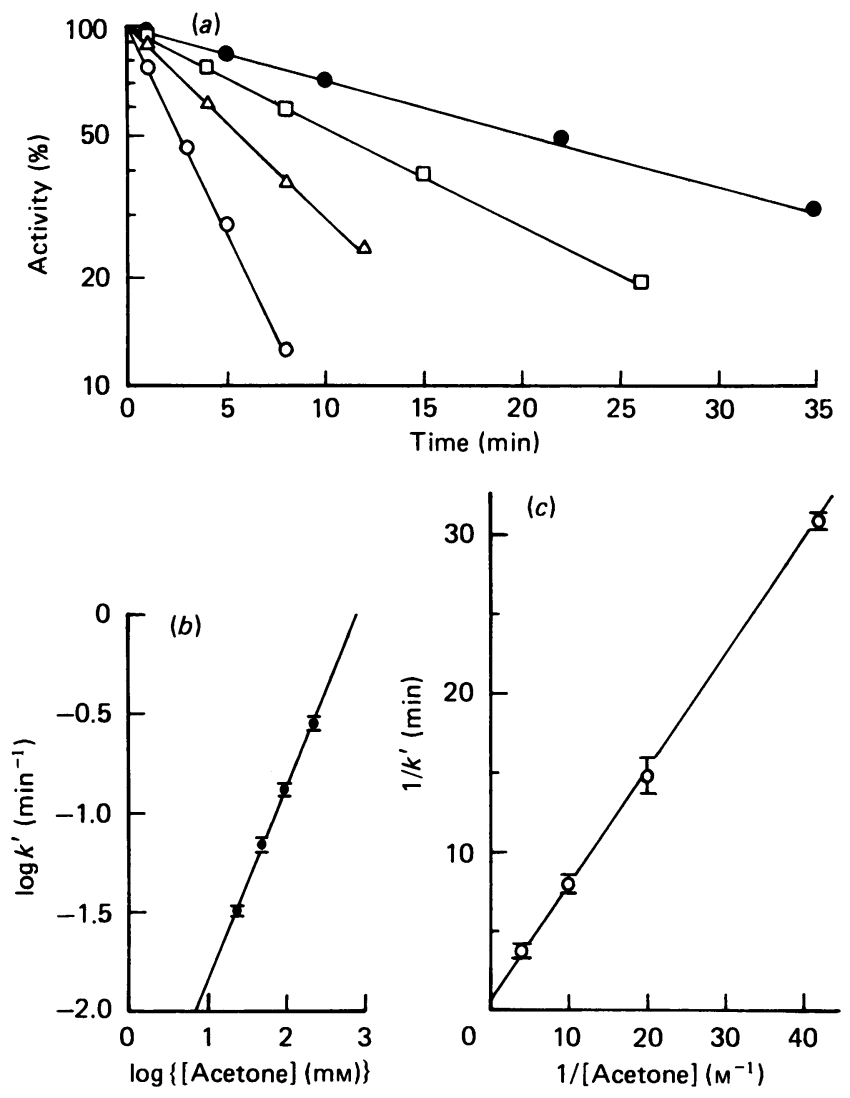

Fig. 3. Inactivation of Drosophila melanogaster $\mathbf{A d h}^{\mathrm{s}}$ with $\mathrm{NAD}^{+}$and acetone

(a) Semi-logarithmic plots of inactivation versus time. The reaction mixture consisted of $1.5 \mu \mathrm{M}-\mathrm{Adh}^{\mathrm{s}}, 3.1 \mathrm{mM}-\mathrm{NAD}^{+}$ and various acetone concentrations $(O, 240 \mathrm{~mm} ; \triangle$, $100 \mathrm{~mm}$; $\square, 50 \mathrm{~mm}$;, $24 \mathrm{~mm}$ ) in $0.1 \mathrm{M}$-Tris $/ \mathrm{HCl}$ buffer, pH 8.6, at $23.5^{\circ} \mathrm{C}$. (b) Double-logarithmic plot of resulting rate constants versus acetone concentrations. Reaction conditions were as in $(a)$ except that each point is the average of three $\mathrm{NAD}^{+}$concentrations (mean \pm S.D.), $9.8 \mathrm{mM}, 6.9 \mathrm{~mm}$ and $3.1 \mathrm{~mm}$. (c) Double-reciprocal plot of rate constants versus acetone concentrations. Reaction conditions were as in $(b)$.

sulphate/Nitro Blue Tetrazolium method destabilizing the assumed $\mathrm{NAD}(\mathrm{H})$-carbonyl complex present in naturally occurring Adh-3 and Adh-1 [45,46]. It is known that $\mathrm{NAD}^{+}$can be reduced non-enzymically to $\mathrm{NADH}$ by $\mathrm{NAD}(\mathrm{H})$-pyruvate and $\mathrm{NAD}(\mathrm{H})$-acetone adducts at basic $\mathrm{pH}$ [47]. To determine whether the faint activity zone observed for the converted enzyme after electrophoresis was a result of a non-enzymic reduction of $\mathrm{NAD}^{+}$or phenazine methosulphate/Nitro Blue Tetrazolium by the bound NAD $(\mathrm{H})$-acetone adduct, the starch gel was first exposed to an activity staining mixture that contained only phenazine methosulphate/ Nitro Blue Tetrazolium or $\mathrm{NAD}^{+} /$phenazine methosulphate/Nitro Blue Tetrazolium in $0.1 \mathrm{M}$-glycine/ $\mathrm{NaOH}$ buffer, $\mathrm{pH}$ 9.5. Neither the native $\mathrm{Adh}^{\mathrm{s}}$ enzyme nor the converted enzyme was stained, but on adding ethanol to the latter mixture activity zones appeared for both of the isoenzymes. This shows that the staining of the converted enzyme was not a result of a non-enzymic reduction of the staining reagents, but a real enzymic activity.
The mechanism of the conversion process can thus be described as follows. The starting event is the formation of a binary enzyme-NAD ${ }^{+}$complex (see Scheme 1). This is followed by the formation of a reversible ternary enzyme-NAD ${ }^{+}$-acetone complex. Now an irreversible process occurs and the enzyme-NAD $(\mathrm{H})$-acetone complex (Adh-1) appears. If there is a physiological function of the conversion process it is still unknown. It may be associated with the reported aldehyde dehydrogenase activity of the enzyme [48].

\section{REFERENCES}

1. Johnson, F. M. \& Dennistone, C. (1964) Nature (London) 204, 906-907

2. Grell, E. H., Jacobsen, K. B. \& Murphy, J. B. (1965) Science 149, 80-82

3. Grell, E. H., Jacobsen, K. B. \& Murphy, J. B. (1968) Ann. N.Y. Acad. Sci. 151, 345-351

4. Ursprung, H. \& Leone, J. (1965) J. Exp. Zool. 160, $147-154$

5. Vigue, C. L. \& Johnson, F. M. (1973) Biochem. Genet. 9, 213-217

6. Jacobsen, K. B., Murphy, J. B. \& Hartman, F. C. (1970) J. Biol. Chem. 245, 1075-1083

7. Jacobsen, K. B., Murphy, J. B., Knopp, J. A. \& Ortiz, J. R. (1972) Arch. Biochem. Biophys. 149, 22-35

8. Schwartz, M., Gerace, L., O’Donnell, J. \& Sofer, W. (1975) in Isoenzymes (Markert, C. L., ed.), vol. 1, pp. 725-751, Academic Press, New York and London

9. Schwartz, M. \& Sofer, W. (1976) Nature (London) 263, 129-130

10. Schwartz, M., O'Donnell, J. \& Sofer, W. (1979) Arch. Biochem. Biophys. 194, 365-378

11. Papel, J., Henderson, M., van Herrewege, J., David, J. \& Sofer, W. (1979) Biochem. Genet. 17, 553-563

12. Winberg, J. O., Thatcher, D. R. \& McKinley-McKee, J. S. (1983) Biochem. Genet. 21, 63-80

13. Chambers, G. K., Wilks, A. V. \& Gibson, J. B. (1984) Biochem. Genet. 22, 153-168

14. van Delden, W. (1982) Evol. Biol. 15, 187-222

15. Thatcher, D. R. (1977) Biochem. J. 163, 317-327

16. Thatcher, D. R. (1980) Biochem. J. 187, 875-886

17. Chambers, G. K., Laver, W. G., Campbell, S. \& Gibson, J. B. (1981) Proc. Natl. Acad. Sci. U.S.A., 78, 3103-3107

18. Chambers, G. K., Wilks, A. V. \& Gibson, J. B. (1981) Aust. J. Biol. Sci. 34, 625-637

19. Chambers, G. K. (1984) Biochem. Genet. 22, 529-549

20. Gibson, J. B., Chambers, G. K., Wilks, A. V. \& Oakeshott, J. B. (1980) Aust. J. Biol. Sci. 33, 479-489

21. Juan, E. \& Gonzalez-Duarte, R. (1980) Biochem. J. 189, 105-110

22. Bodmer, M. \& Ashburner, M. (1984) Nature (London) $309,425-430$

23. Moxon, L. N., Holmes, R. S., Parsons, P. A., Irving, M. G. \& Doddrell, D. M. (1985) Comp. Biochem. Physiol. B 80, 525-535

24. Kreitman, M. (1983) Nature (London) 304, 412-417

25. Winberg, J. O., Thatcher, D. R. \& McKinley-McKee, J. S. (1982) Biochim. Biophys. Acta 704, 7-16

26. Winberg, J. O., Thatcher, D. R. \& McKinley-McKee, J. S. (1982) Biochim. Biophys. Acta 704, 17-25

27. Hovik, R., Winberg, J. O. \& McKinley-McKee, J. S. (1984) Insect Biochem. 14, 345-351

28. Jacobsen, K. B. (1968) Science 159, 324-325

29. Jacobsen, K. B. \& Pfuderer, P. (1970) J. Biol. Chem. 245, 3938-3944

30. Ursprung, H. \& Carlin, L. (1968) Ann. N.Y. Acad. Sci. 151, 456-475 
31. Knopp, J. A. \& Jacobsen, K. B. (1972) Arch. Biochem. Biophys. 149, 36-41

32. Kornberg, A. (1957) Methods Enzymol. 3, 876-882

33. Wallenfels, K. \& Christian, W. (1957) Methods Enzymol. 3, 882-884

34. Winberg, J. O., Hovik R. \& McKinley-McKee, J. S. (1985) Biochem. Genet. 23, 205-216

35. Reynolds, C. H. \& McKinley-McKee, J. S. (1969) Eur. J. Biochem. 10, 474-478

36. Levy, H. M., Leber, P. D. \& Ryan, E. M. (1963) J. Biol. Chem. 191, 3654-3659

37. Carlson, G. M. (1984) Biochim. Biophys. Acta 789, 347-350

38. Theorell, H. \& Yonetani, T. (1963) Biochem. Z. 338, 537-553

39. Winberg, J. O., Hovik, R., McKinley-McKee, J. S., Juan, E. \& Gonzalez-Duarte, R. (1986) Biochem. J. 235, 481490

Received 9 July 1987/2 October 1987; accepted 30 November 1987
40. Colowick, S. P., Kaplan, N. O. \& Ciotti, M. M. (1951) J. Biol. Chem. 191, 445-459

41. Shifrin, S. \& Kaplan, N. O. (1960) Adv. Enzymol. Relat. Subj. Biochem. 22, 337-415

42. Kosower, E. M. (1962) Biochim. Biophys. Acta 56, 474-479

43. Levitas, N., Robinson, J., Rosen, F., Huff, J. W. \& Perlzweig, W. A. (1947) J. Biol. Chem. 167, 169-175

44. Burton, R. M. \& Kaplan, N. O. (1954) J. Biol. Chem. 206, 283-297

45. Heinstra, P. W. H.,. Eisses, K. Th., Scharloo, W. \& Thörig, G. E. W. (1986) Comp. Biochem. Physiol. B 83, 403-408

46. Heinstra, P. W. H., Scharloo, W. \& Thörig, G. E. W. (1986) Comp. Biochem. Physiol. B83, 409-414

47. diSabato, G. (1970) Biochemistry 9, 4594-4600

48. Heinstra, P. W. H., Eisses, K. Th., Choonen, W., Aben, W., deWinter, A. J., Van der Horst, D. J., Marrewijk, W. J. A., Beenakkers, A. M. Th., Scharloo, W. \& Thörig, G. E. W. (1983) Genetica 60, 129-137 